\title{
How to Develop a Competitive Master of Science Program in Management Information Systems with a Focus on Enterprise Systems: A Case Study
}

\author{
Kakoli Bandyopadhyay \\ Lamar University \\ Soumava Bandyopadhyay \\ Lamar University
}

\begin{abstract}
A proposal for a competitive Master of Science program in Management Information Systems with a focus on Enterprise Systems is presented. The program, offered both face-to-face and online, is particularly positioned toward exposing students to Enterprise Systems thereby offering them a competitive edge in the global job market. The students graduating from this program will work as Business Analysts, Enterprise Resource Planning Consultants, Business Intelligence Designers, Systems Analysts, Data Analysts, etc. The success of the program can be measured through student job placement and student achievement of learning outcomes.
\end{abstract}

\section{INTRODUCTION}

An Enterprise System (ES) is an information system that integrates the core business functions seamlessly across the organization (Davenport, 1998). Enterprise Systems have become the backbone of many organizations today. These allow businesses to achieve high performance through distinctive capabilities, thereby becoming one of the fastest growing areas within Information Systems. Some of the benefits of Enterprise Systems are: 1) automation of business processes; 2) reduction in the cost of doing business; 3) improvement in customer service; 4) better decision making; and 5) improvement in overall profitability (Hunt \& Chico, 2015; Panetto et al., 2015; Zeng et al., 2011).

In this paper, we propose a framework for a specialized, STEM (Science, Technology, Engineering, and Mathematics) certified, graduate program in Management Information Systems (MIS) with a focus on Enterprise Systems. The program is proposed by the Department of Information Systems in the College of Business of a Public University in the State of Texas. The framework for the development of the proposal for a graduate program in Management Information Systems (MIS) comprises of the establishment of three important steps: First, the need for an MS program in MIS with an emphasis on Enterprise Systems; second, the quality of the program; and third, the cost and the funding sources for the proposed program. The need for an MS program in MIS can be built by analyzing the job market needs, the student demand, and the target market and enrollment projections. The quality of the proposed program can be established through degree requirements, curriculum offered, faculty credentials, student admission requirements, library resources, availability and adequacy of facilities and equipment,obtaining 
accreditation in the discipline, and the evaluation process to assess the quality and the effectiveness of the proposed program. The cost and funding sources for five years have to be reported. The estimation of the costs will emanate from categories such as the personnel, facilities and equipment, library, supplies, and material and other costs, including costs for course development. The framework is presented in Figure 1. Each component of the framework is then described in detail.

FIGURE 1

THE FRAMEWORK TO PROPOSE AN MS PROGRAM IN MIS

\begin{tabular}{|rl|}
\hline Program Need & \\
- & Job Market Need \\
- & Student Demand \\
- & Target Market and Enrollment Projections \\
\hline Program Quality \\
$-\quad$ Degree Requirements \\
$-\quad$ Curriculum \\
- & Faculty Requirements \\
- & Admission Requirements \\
- & Library Resources \\
- & Facilities and Equipment \\
- & Accreditation in the Discipline \\
- & Evaluation Process \\
\hline Costs and Funding \\
- & Personnel Cost \\
- & Facilities and Equipment Cost \\
- & Libraries, Supplies, and Material Cost \\
- & Other Costs \\
- & Reallocated Funds \\
- & Anticipated New Formula Funding \\
- & Special Item Funding \\
- & Designated Tuition and Fees \\
\hline
\end{tabular}

\section{PROGRAM NEED}

The need for an MS program in MIS with an emphasis in Enterprise Systems can be assessed by analyzing the job market need, the student demand, and the target market and enrollment projections. Each component is described below:

\section{Job Market Need}

Global spending on information technology will reach $\$ 3.658$ trillion in 2018 , according to a new report from Gartner, up 4.3 percent over this year's projected \$3.508 trillion (Bolkan, 2017). The fourth largest category, enterprise software, will see the fastest growth rate across both years, improving 8.5 percent from 2016 to 2017 for a total spend of $\$ 354$ billion and continuing to grow at 9.4 percent to reach $\$ 387$ billion in 2018 .

Enterprise Resource Planning (ERP) Systems are used by almost all Fortune 500 companies, and most of those companies use SAP. The Enterprise System used in the MS program will be SAP R/3- the world's leading producer of business software. Today, more than 350,100 customers in more than 180 countries run SAP applications. SAP customers include 87\% of the Forbes Global 2000 companies, 98\% of the 100 most valued brands, and $100 \%$ of the Dow Jones top-scoring sustainability companies. SAP customers produce $78 \%$ of the world's food and $82 \%$ of the world's medical devices. Seventy-six percent of the world's transaction revenue touches an SAP system (SAP Global Corporate Affairs, 2018). As a member of the SAP University Alliance, we will provide students with hands-on experience using SAP, 
the ERP software to be used in the MS curriculum. Executives from local, national, and multinational companies consider ERP experience to be a significant differentiating factor when reviewing resumes and selecting candidates for job interviews.

Our own survey of MBA and engineering students taking ERP courses and working with Enterprise Systems reveals that companies such as Apple, Associa, Cognizant Technology Solutions, Tris Pharma, Navi Health, SilverXis Inc., Cotiviti, Sodexo, NYC Services, Plastechs, Kikkerland, The J.M. Smucker Company, Genomic Health Inc., etc. have recruited our students. Some of the job titles that the students hold are: Business Analyst, Computer System Analyst, Systems Analyst, Consultant, etc.

The University Career Center assists students and alumni with career planning and development, resume preparation, interview skills, career consultation, and employer connections. Each year, more than $1000 \mathrm{MIS} /$ Enterprise Systems-related positions are posted with the Career Center job database, making it the best source for information systems jobs for the students. Career fairs take place twice a year with local and national employers participating.

Also, the department has an innovative plan for placement. We have brought our undergraduate MIS and MBA-ERP students (past and present) under one umbrella. We have groups on Facebook and LinkedIn. These groups provide a common platform for our MIS students to engage in career advancement opportunities. We will add the MS students in this group too. It is a novel way of competition through cooperation. Current students get help from former students. Moreover, the present students return the support when they are gainfully employed and are in a position to help. It is selfsustaining, and the MIS students (past and present) together compete with MIS students from other universities to get the jobs that are available. The former students often coach the current students for the entry-level positions in their organization.

\section{Student Demand}

The student demand for the proposed program needs to be assessed next. There are several ways of assessing the student demand. First, the MIS enrollment data from the state's higher education data store can be consulted. The enrollment data in Table 1 below from the Texas HigherEd (http://www.txhighereddata.org/) site shows that the total enrollment for MS in MIS in 2015 in Public Universities in Texas was: 2729, in 2016: 2965, and in 2017: 2740. The total number of degrees awarded in 2017 is 1335 . Even though there is a slight drop in enrollment from 2016 Fall to 2017 Fall, this is speculated to be primarily due to the national trend of a decline in international student enrollment in 2017. 
TABLE 1

MS IN MIS PROGRAMS

\begin{tabular}{|c|c|c|c|c|}
\hline University Name & $\begin{array}{r}\text { Enrollment - } \\
2015 \text { Fall } \\
\end{array}$ & $\begin{array}{r}\text { Enrollment - } \\
2016 \text { Fall } \\
\end{array}$ & $\begin{array}{r}\text { Enrollment }-2017 \\
\text { Fall } \\
\end{array}$ & $\begin{array}{r}\text { Degree Awarded } \\
(2017) \\
\end{array}$ \\
\hline $\begin{array}{l}\text { University of Texas Rio } \\
\text { Grande Valley }\end{array}$ & 52 & 45 & 38 & 14 \\
\hline University of Texas at Dallas & 1056 & 1218 & 1064 & 578 \\
\hline Texas Tech University & 95 & 27 & 34 & 25 \\
\hline $\begin{array}{l}\text { University of Texas at San } \\
\text { Antonio }\end{array}$ & 55 & 79 & 78 & 29 \\
\hline $\begin{array}{l}\text { University of Texas at } \\
\text { Arlington }\end{array}$ & 195 & 268 & 264 & 128 \\
\hline $\begin{array}{l}\text { University of Houston -Clear } \\
\text { Lake }\end{array}$ & 278 & 224 & 149 & 129 \\
\hline $\begin{array}{l}\text { University of Houston - } \\
\text { Victoria }\end{array}$ & 66 & 61 & 46 & 21 \\
\hline Tarleton State University & 53 & 48 & 56 & 9 \\
\hline University of Texas at Austin & 185 & 204 & 249 & 76 \\
\hline University of North Texas & 172 & 277 & 264 & 82 \\
\hline Texas A \& M International & 89 & 52 & 32 & 8 \\
\hline Texas A \& M University & 269 & 269 & 254 & 157 \\
\hline Texas A\&M Central Texas & 22 & 31 & 38 & 20 \\
\hline Texas Southern University & 49 & 53 & 46 & 20 \\
\hline Prairie View A\&M University & 25 & 38 & 48 & 13 \\
\hline West Texas A\&M University & 68 & 71 & 80 & 26 \\
\hline Total & 2729 & 2965 & 2740 & 1335 \\
\hline
\end{tabular}

Next, if the university offers an MIS/ES concentration in the MBA program, the enrollment in that concentration needs to be examined. We offer six graduate MIS courses in different concentrations in the MBA program and in the ES graduate certificate. We have had 30 MBA students in the ES concentration in the last five years. We, however, have generated 5,037 student credit hours from 2012-2016 from graduate students including those from engineering management, industrial engineering, electrical engineering, and computer science. Students from various disciplines benefit from taking these courses, establishing the demand for ES-based courses. Also, the MS programs in peer schools have to be considered. None of our peer schools has an MS in MIS/ES program. Lastly, we need to note that our Department office gets numerous inquiries from prospective graduate students about the availability of an ES-based MS program on a regular basis. 


\section{Target Market and Enrollment Projections}

The target market for the program and the enrollment projections will now have to be established. On the basis of the job market need and the student demand established above, it can be inferred that in the online space, the target market will consist of domestic IT industry employees, business professionals working with enterprise systems, and MIS students from the undergraduate programs of other business schools. We also anticipate marketing the program to graduates from other non-business disciplines as a means of earning a professional degree. Also, it is expected that the face-to-face program will be attractive to international students from countries where Enterprise Systems are in demand and are in the early stages of implementation. An MS in MIS/ES will provide a clear and distinctive opportunity to students to enter into a professional career as an ES consultant and/or Business Analysts. Table 2 shows the estimated cumulative head count and full-time student equivalent (FTSE) enrollment for the first five years of the program. We plan to offer the program both face-to-face and online. The face-to-face program is intended for full time international students, and hence it is assumed that the students would finish the whole program of thirty credit hours in one year. The online program is proposed for working domestic students, and it is assumed that these students would need two years to finish the program. The enrollment in both programs is conservatively estimated to be at the lower end of other established programs. Also, the anticipated attrition rate is $15 \%$. We assume that full-time students will take one year to complete the program, and the part-time students will take two years to complete the program. The attrition rate is applied to the full-time students during their year in the program, and to the part-time students in Year 2.

TABLE 2

ENROLLMENT PROJECTIONS OVER FIVE YEARS

\begin{tabular}{lccccc}
\hline YEAR & 1 & 2 & 3 & 4 & 5 \\
\hline Headcount & 15 & 40 & 65 & 85 & 100 \\
FTSE & 10 & 25 & 40 & 53 & 63 \\
Attrition & .75 & 3 & 5.25 & 7.5 & 9 \\
Graduates & 4 & 17 & 29 & 42 & 51 \\
\hline
\end{tabular}

\section{PROGRAM QUALITY}

Our proposed program will be comparable to MS in MIS programs of leading-edge schools with an emphasis in Enterprise Systems. No peer university in the state of Texas currently has a comparable program. Enterprise Systems allow businesses to achieve high performance through distinctive capabilities and is one of the fastest growing areas within Information Systems. The program will be laden with commercial, in-demand software such as SAP, Oracle, Primavera P6, Tableau, Advanced Excel and Access, and Salesforce. SAP TERP10 certification will be offered to students. Also, the program will seek AACSB accreditation as a separate program. As the program grows, consideration can be given to offering specialty or track areas such as data analytics, web security, etc. The quality of the proposed program will be assessed through degree requirements, curriculum offered, faculty credentials, student admission requirements, library resources, availability and adequacy of facilities and equipment, obtaining accreditation in the discipline, an evaluation process to assess the quality and the effectiveness of the proposed program. Each of the components of program quality is discussed below. 


\section{Degree Requirements}

Most MS programs in MIS require a maximum of 30-36 credit hours. We can have three categories of requirements: required courses, prescribed electives, and free electives. In addition, we can also have an internship requirement. Our proposed program has two categories, as described in Table 3.

TABLE 3

\section{DEGREE REQUIREMENTS}

\begin{tabular}{lc}
\hline Category & Semester Credit Hours \\
\hline Required Courses (6) & 18 \\
Prescribed Electives (4/6) & $12 / 18$ \\
Free Electives (0) & 0 \\
Other (Specify, e.g., internships, clinical work) & 0 \\
TOTAL & 30 \\
\hline
\end{tabular}

\section{Curriculum}

Our proposed program is comparable to MS in MIS programs with an emphasis in Enterprise Systems. As the program grows, consideration can be given to offering specialty or track areas. Tables 4 and 5 identify the required courses and prescribed electives of the program.

TABLE 4

\section{REQUIRED COURSES}

\begin{tabular}{l}
\hline Required Courses (6/6) \\
\hline ERP Overview with SAP HEC Simulation, MM, SD, PP, and FICO \\
ERP-E-Commerce with SAP With SAP FIORI, and BUILD, and HANA Cloud Platform \\
Business Intelligence with SAP BW, Tableau, Crystal Reports, SAP BO \\
Supply Chain Management with SAP \\
ES/CRM - with SAP and Salesforce \\
Data Mining and Predictive Analytics with SAP \\
\hline
\end{tabular}

TABLE 5

PRESCRIBED ELECTIVE COURSES

\begin{tabular}{l}
\hline Prescribed Elective Courses (4/6) \\
\hline IT Project Management \\
Information Assurance and Security \\
Database Management Systems \\
Introduction to Programming for Business Solutions \\
Healthcare Info. Systems \\
Managerial Decision Making \\
\hline
\end{tabular}

\section{Faculty}

The anticipated faculty resources needed in the program from year one through year five have to be assessed. We currently have faculty with sufficient knowledge and experience to meet the teaching requirements for the MS in MIS/ES program. As the program grows, we may need to hire more faculty to meet the increased demand in teaching. With current projections, we are anticipating no faculty hires in the first three years of the program. As the program grows, we may need to hire one additional faculty in year four and five respectively. 


\section{Admission Requirements}

Our proposed program will admit applicants with a 3.0 GPA in their Bachelor's degree or a 3.0 GPA in the last 60 hours of their Bachelor's degree, as long as the total Bachelor's degree GPA is no lower than 2.5, without a GMAT/GRE test requirement. If an applicant has at least 15 post-graduate hours, these hours may be used in tandem with a Bachelor's degree with a GPA of between 2.5 and 2.999 to establish a GPA in the last 60 hours. Those applicants who do not have the minimum GPA of 3.0 in either the Bachelor's or the last 60 hours but do have a GPA between 2.5 and 2.999 in the last 60 hours will be required to take the GMAT/GRE. The current College of Business policy is that new applicants admitted with a GRE/GMAT requirement will be able to take 9 credit hours prior to providing the required GMAT/GRE score. Also, the GMAT/GRE requirement may be waived for applicants with 3 or more years of professional experience. For students taking the GMAT, we will require a minimum score of 1,000 according to the formula: (GPA x 200) + GMAT score. For students taking the GRE, our minimum score requirement will be 428 according to the formula: (GPA x 50) + GRE Verbal + GRE Quantitative. The undergraduate students will be welcomed to take courses in the MS in MIS program provided they have a minimum of 2.75 cumulative undergraduate GPA. The undergraduate students may take a maximum of 9 graduate credit hours before their undergraduate degree is conferred.

\section{Library Resources and Facilities and Equipment}

We will offer course materials through Blackboard, the course Management software used in the College of Business. We are a member of the SAP Academic Alliance, the Oracle Academy, and the Salesforce Trailhead for Students. All software used in the program are downloadable by the students free of cost. Also, our online library offers a vast array of scholarly and professional research materials. A service oriented library staff will assist in the use of reference materials, documents, special collections, reserve materials and instructional media. Additionally, students have access to the collections of 51 other publicly funded colleges and universities through the TexShare program. Thus, the library resources currently available are adequate for the program. The facilities and equipment necessary for this proposed program are currently adequate and available.

\section{Accreditation}

All graduate programs offered by our College of Business are accredited by the AACSB. The MS in MIS/ES will also seek AACSB accreditation as a separate program. A separate process of assessment will be established. A new evaluation process will be established to assess the quality and effectiveness of the program.

\section{Evaluation}

Using the Weave Assessment and Planning Management System for Institutional Effectiveness, the courses in place are assessed once a year to ensure that they meet the established goals and objectives. Each objective is measured and the findings are compared with the benchmarked target. Action plan is formulated and followed through if the target is not met. The new courses will be assessed using the same evaluation system. Also a new evaluation process will be established to assess the quality and effectiveness of the new degree program as a whole through student job placement and student achievement of learning outcomes. Also, our COB Director of Assessment and Accreditation will be in charge of the evaluation process to ensure that the program gets AACSB accredited.

\section{COSTS AND FUNDING}

The costs and funding sources need to be established for a period of five years. The costs will have to be estimated for personnel, facilities and equipment, library, supply and materials, and other (such as administrative, travel, etc.) categories. Within personnel, new faculty hires, graduate assistants, and technical support personnel have to be considered. If existing faculty will contribute to the program, the cost of hiring adjunct instructors to cover courses previously taught by faculty who would teach in new 
program has to be estimated. The five year funding has to be estimated on the basis of anticipated formula funding, designated tuition and fees, and reallocated and special item funding. The formula funding should be included only for years three through five of the program and should reflect enrollment projections for years three through five. Table 6 shows the five year costs and funding sources.

TABLE 6

FIVE-YEAR COSTS AND FUNDING SOURCES

\begin{tabular}{ll}
\hline Five-Year Cost & Five-Year Funding \\
\hline Personnel & Reallocated Funds \\
Facilities and Equipment & Anticipated New Formula Funding \\
Library, Supplies, and Materials & Special Item Funding \\
Other (Marketing fee) & Designated tuition and fees \\
Total Costs & Total Funding \\
\hline
\end{tabular}

\section{SUMMARY}

The framework to develop a competitive, STEM certified, 30 hour, one-year Master of Science program in Management Information Systems with a focus on Enterprise Systems is discussed in the paper. The program is intended to increase the graduate student enrollment in the College of Business. Enterprise Systems-related courses which are already being offered in various concentrations in the MBA program can be reused. The program will seek AACSB accreditation as a separate program. The program will introduce an innovative curriculum in MIS with cutting-edge software, to be offered to diverse student population consisting of both domestic and international students, with a high level of accessibility (the program may be offered both face-to-face and online), and to be taught by qualified faculty committed to teaching and research. The success of the program can be measured through student job placement and student achievement of learning outcomes.

\section{REFERENCES}

Bolkan, J. (2017). IT Spending to Top \$3.65 Trillion in 2018. Retrieved from https://thejournal.com/articles/2017/10/04/it-spending-to-top-3.65-trillion-in-2018.aspx

Davenport, T.H. (1998). Putting the Enterprise into the Enterprise System. Harvard Business Review, 76, (4), 121-131.

Hunt, C.S. \& Choi, H. (2015). Critique of the Empirical Literature on Enterprise Systems - Over a Half Decade of Research. Journal of Management Information and Decision Sciences, 18(1), 1-12.

Panetto, H., Zdravkovic, M., Jardin-Goncalves, R., Mezgar. I. (2015). New Perspectives for the Future Interoperable Enterprise Systems. Computers in Industry, 79(6). 47-63.

SAP Global Corporate Affairs. (2018). Retrieved from https://www.sap.com/corporate/en/documents/2017/04/4666ecdd-b67c-0010-82c7eda71af511fa.html

Zeng, S.X., Xie, X.M., Tam, C.M., Shen, L.Y. (2011). An Empirical Examination of Benefits from Implementing Integrated Management Systems (IMS). Total Quality Management \& Business Excellence, 22(2), 173-186. 